\section{Desensitization to Filgrastim in a 2-Year-Old Girl With a Vaginal Endodermal Sinus Tumor}

González-Cavero L, Gómez-Traseira C, Fiandor A, Entrala A, Quirce S

Department of Allergy, Hospital La Paz Institute for Health Research (IdiPAZ), Madrid, Spain

J Investig Allergol Clin Immunol 2019; Vol. 29(4): 329-330 doi: 10.18176/jiaci.0399

Key words: Desensitization. Drug hypersensitivity. Filgrastim. Children.

Palabras clave: Desensibilización. Hipersensibilidad a drogas. Filgrastim. Niños.

Recombinant human granulocyte-stimulating factors (G-CSF) are administered to cancer patients to minimize the intensity and duration of neutropenia associated with chemotherapy and radiotherapy. The commercially available members of this family in Spain are filgrastim (Neupogen, Amgen SA), lenograstim (Granocyte, Italfarmaco SA), and pegfilgrastim (Neulasta, Amgen SA).

The drugs are usually administered subcutaneously. Recombinant human G-CSF are generally considered to be safe, and anaphylactic episodes and hypersensitivity reactions caused by these drugs are rare $[1,2]$.

Desensitization protocols have been reported for adults, but not for children [3].

A 2-year-old girl with no known allergies was diagnosed with a vaginal endodermal sinus tumor at the age of 18 months and initially treated at Badajoz Hospital, Badajoz, Spain. She experienced generalized urticaria, facial angioedema, and oculonasal itching during her third cycle of filgrastim $(5 \mu \mathrm{g} / \mathrm{kg} / \mathrm{d} \times 14 \mathrm{~d}) 4$ hours after administration. She required treatment with dexchlorpheniramine and prednisolone and experienced similar symptoms in the subsequent 4 cycles. In one of the cycles, filgrastim was replaced by lenograstim $(2 \mu \mathrm{g} / \mathrm{kg} / \mathrm{d})$, and, despite administration of premedication with dexchlorpheniramine $(0.4 \mathrm{mg} / \mathrm{mL})$ and prednisolone $(7 \mathrm{mg} / \mathrm{mL})$, an identical reaction occurred with the first dose, thus leading to withdrawal of the drug.

Two months later, the tumor recurred, and reintroduction of the drug was mandatory. Therefore, the patient was referred to our allergy department for assessment. After informed consent was obtained, the patient underwent a routine allergy work-up (skin tests). Skin prick testing (SPT) applied with the commercial preparation of filgrastim (30 MU $0.3 \mathrm{mg} / \mathrm{mL}$ ) yielded a negative result.

An intravenous desensitization protocol was carried out with filgrastim because the reaction was thought to be allergic in nature, the drug was essential for appropriate treatment, and treatment was now urgent. The patient reached the dose recommended by the hematology-oncology department with no adverse reactions.

The procedure was performed at the hospital under close supervision by an allergist and nurse and with emergency medications available. We used a 12-step protocol, which was adapted to the dose prescribed by the hematologist-oncologist and to the patient's weight (Table).

The procedure was carried out twice. In the first, a dose of $120 \mu \mathrm{g}(10 \mu \mathrm{g} / \mathrm{kg} / \mathrm{d})$ was reached to ensure mobilization of colonies and thus achieve apheresis. The patient subsequently maintained this dose at home subcutaneously for 4 days, with no complications.

A second desensitization protocol (necessary because of recurrence of the tumor) applied 1 month later enabled a dose of $60 \mu \mathrm{g}(5 \mu \mathrm{g} / \mathrm{kg} / \mathrm{d})$ to be reached. The patient required subcutaneous treatment at home for 14 days.

Forty-eight hours after the last dose of filgrastim, a dose of $60 \mu \mathrm{g}$ was again prescribed owing to a significant decrease in the neutrophil count. The drug was administered over 90 minutes (this usually takes 20 minutes) without premedication and without adverse effects.

The patient continued with this subcutaneous regimen for a further 3 days. Tolerance was excellent.

Severe adverse effects of recombinant human G-CSF are rare. Anaphylactic episodes are extremely rare, although hypersensitivity reactions have been reported [1].

The mechanism of these reactions is unknown.

In the case we report, skin prick tests with the drug were negative, possibly because of the implication of a non-IgEmediated underlying immunological mechanism or because the skin prick tests were not sensitive enough.

Table. Desensitization Protocol in 12 Steps With Neupogen

\begin{tabular}{lcccccc} 
Step Solution & $\mu / \mathrm{L}$ & $\begin{array}{c}\text { Flow, } \\
\mathrm{mL} / \mathrm{h}\end{array}$ & $\begin{array}{c}\text { Time, } \\
\mathrm{min}\end{array}$ & $\begin{array}{c}\text { Dose } \\
\text { Administered, } \mu \mathrm{g}\end{array}$ & $\begin{array}{c}\text { Cumulative } \\
\text { Dose, } \mu \mathrm{g}\end{array}$ \\
\hline 1 & $\mathrm{~A}$ & 0.03 & 2 & 15 & 0.01 & 0.01 \\
2 & $\mathrm{~A}$ & 0.03 & 4 & 15 & 0.03 & 0.04 \\
3 & A & 0.03 & 8 & 15 & 0.06 & 0.10 \\
4 & A & 0.03 & 16 & 15 & 0.12 & 0.22 \\
5 & B & 0.3 & 3 & 15 & 0.22 & 0.45 \\
6 & B & 0.3 & 6 & 15 & 0.45 & 0.90 \\
7 & B & 0.3 & 12 & 15 & 0.90 & 1.80 \\
8 & B & 0.3 & 24 & 15 & 1.80 & 3.60 \\
9 & C & 3 & 4 & 15 & 3.00 & 6.60 \\
10 & C & 3 & 8 & 15 & 6.00 & 12.60 \\
11 & C & 3 & 16 & 15 & 12.00 & 24.60 \\
$12^{\mathrm{a}}$ & C & 3 & 30 & 30 & 45.00 & 69.60 \\
$12^{\mathrm{a}}$ & $\mathrm{C}$ & 3 & 30 & 60 & 96.00 & 120.60 \\
\hline
\end{tabular}

Solution A (1/100): $5 \mathrm{~mL}$ of solution $\mathrm{B}+45 \mathrm{~mL}$ of physiological saline solution.

Solution B (1/10): $5 \mathrm{~mL}$ of solution $\mathrm{C}+45 \mathrm{~mL}$ of physiological saline solution.

Solution C: $1 \mathrm{~mL}$ of $0.3 \mathrm{mg} / \mathrm{mL}+99 \mathrm{~mL}$ of $5 \mathrm{~mL}$ physiological saline solution.

${ }^{\text {aStep }} 12$ is presented twice, corresponding to the 2 occasions in which the protocol was applied, reaching $120 \mu \mathrm{g}$ and $69.60 \mu \mathrm{g}$ on the first and the second occasion, respectively. 
Nowadays, desensitization is indicated in cases of hypersensitivity reactions to a first-line drug for which no equivalents are available. It is achieved by progressively increasing the dose of the drug until the necessary dose is reached and a state of tolerance that protects against anaphylaxis is induced [4].

Although anaphylaxis to G-CSF and granulocyte-monocyte colony-stimulating factor has been reported, desensitization protocols have rarely been described [5].

In the present case, it is interesting that the patient tolerated the new filgrastim regimen despite having been 48 hours without receiving the drug. This can be explained by the pharmacokinetics of the drug, since the median serum elimination half-life of filgrastim after a single subcutaneous dose ranged from 2.7 hours to 5.7 hours. The half-life can increase after 7 days of administration to 8.5-14 hours. Because the complete elimination of a drug is approximately 5 halflives, the drug was probably still present in the patient's body because she had been receiving it for several days [6].

One valid explanation could be that reducing the infusion rate was sufficient to ensure tolerance.

According to the clinical history, the parents believed that this step was carried out in Badajoz Hospital, although there was no record of it; therefore, it was not chosen as the first option, and we proceeded directly to desensitization as a safer procedure.

Intradermal testing was not performed because the patient required urgent treatment and the result was not going to rule out desensitization. Furthermore, the patient's status precluded oral drug challenge.

The most commonly used intravenous desensitization protocols are standardized 12- to 16-step approaches modeled after in vitro protocols. These can be personalized for all drugs, with adjustment of the target dose, time intervals between doses, and starting dose, as was the case in this report [7].

Our experience suggests that desensitization protocols could be useful and safe for the administration of recombinant human G-CSF drugs in children.

\section{Funding}

The authors declare that no funding was received for the present study.

\section{Conflicts of Interest}

The authors declare that they have no conflicts of interest.

\section{Previous Presentation}

Presented as a poster at the 30th National Conference of Sociedad Española de Alergia e Inmunología Clínica (SEAIC), October 2016, San Sebastián, Spain.

\section{References}

1. Ashok T, Ion C, Jonathan JL, Kristin B, Susan FL. Systemic hypersensitivity reaction mimicking anaphylaxis after first filgrastim administration in a healthy donor. Transfusion. 2013;53(5):1146-7.
2. Batel-Copel L, Mommeja-Marin H, Oudard S, Chauvenet L, Pujade-Lauraine E, Coupier J, et al. Anaphylactic reaction after a first filgrastim (granulocyte-colony Stimulating Factor) inyection. Eur J Cancer. 1995:31 A (13-14)

3. Hronek B, Kulczycki A. A successful desensitization protocol for filgrastim. J Allergy Clin Immunol. 2014.133:942.

4. De las Vecillas-Sánchez L, Garcia-Neuer M, Castells MC. Drug Hypersensitivity and Desensitizations: Mechanisms and New Approaches. Int J Mol Sci. 2017;18(6).

5. Nuñez-Acevedo B, Rodríguez-Jiménez B, Domínguez-Ortega J, González-Montellano E, Ibáñez-Heras N, Enrech-Francés S. Desensitization to lenograstim after a life- threatening reaction to filgrastim. J Investig Allergol Clin Immunol. 2015;25:158-60.

6. Neupogen data sheet, available in: http: // www.aemps.gob. es/cima/pdfs/es/ft/ 64314/FT_64314.pdf. Accessed: March, 2018

7. Castells M. Drug Hypersensitivity and Anaphylaxis in Cancer and Chronic Inflammatory Diseases: The Role of desensitizations. Front Immunol. 2017;8:1472.

8. Adkins DR. Anaphylactoid reaction in a normal donor given granulocyte colony-stimulating factor. J Clin Oncol. 1998; 16:812-3.

9. Tulpule S, Shaw BE, Makoni P, Little AM, Madrigal JA, Goldman JM. Severe allergic reaction with anaphylaxis to G-CSF (lenograstim) in a healthy donor. Bone Marrow Transplant. 2009;44:129-30.

1 Manuscript received September 20, 2018; accepted for publication April 11, 2019.

Lourdes González Cavero

Hospital La Paz

Paseo de la Castellana 261

28061 Madrid

E-mail: lourdesgcavero@gmail.com 